\title{
POLAROGRAPHIC REDUCTION OF HYDROGEN ION IN NON-AQUEOUS SOLVENTS
}

\author{
Philip J. Elving and Michael S. Spritzer \\ University of Michigan, Ann Arbor, Michigan, U.S.A.
}

(Received 7 July 1965. Accepted 21 July 1965)

\begin{abstract}
Summary-The polarographic reduction of hydrogen ion, furnished by dissociation of a Brønsted acid or present in the undissociated Brønsted acid, is reviewed for the situation where a solvent other than water is involved.
\end{abstract}

\section{INTRODUCTION}

THE electrochemical reduction of hydrogen ion in aqueous solution has long been a major problem in electrochemistry, as indicated by the voluminous literature on the subject. The difficulty and complexity involved are well indicated by Frumkin's reviews of one aspect of the situation, that of hydrogen overpotential and adsorption phenomena. ${ }^{18}$ The additional problems introduced when non-aqueous media are used, are well presented in Kolthoff's recent review ${ }^{31}$ of polarography in inert organic solvents; the debt of the present authors to this study will be apparent to the reader. Other useful sources of data on polarography include two monographs by Charlot and collaborators. ${ }^{9.10}$ Bockris $^{5}$ has described the rates of hydrogen evolution in a variety of solvents at a number of different electrodes.

The present review is primarily concerned with the phenomenological aspects of the polarographic reduction of hydrogen ion, furnished by the dissociation of a Brønsted acid or present in the undissociated Brønsted acid, when a solvent other than water is involved; the available literature on hydrogen ion reduction in non-aqueous media is generally not sufficiently systematic and detailed to allow more than general correlations to be made.

Because of the limited and fragmentary data available, hydrogen ion reduction in fused salt media will not be considered. Reference will be made to non-polarographic electrochemical data, where the latter illuminate the polarographic situation. The polarographic reduction of hydrogen ion in aqueous solution will be briefly reviewed to furnish a basis for comparison.

\section{Reduction potentials}

A major problem in dealing with electrochemical data in non-aqueous media is that of expressing potentials obtained in different solvents on a comparable scale; one source of the difficulty is the unknown magnitude of the liquid junction potential between test solution and reference electrode system. The interrelationship between potential scales in different solvents in terms of the Pleskov ${ }^{\mathbf{4 8 . 4 9}}$ and Strehlow ${ }^{\mathbf{3 0 . 5 5}}$ conventions is discussed by Kolthoff. ${ }^{31}$ In the subsequent discussion, the relationships between potentials of hydrogen ion reduction in different solvents will be expressed on several bases in order better to indicate the possible factors involved.

The potential for the half-reaction in aqueous solution

$$
\mathrm{H}^{+}+\mathrm{e} \rightleftharpoons 0.5 \mathrm{H}_{2}
$$


under specified unit activity has been used to fix the potential scale for water as a solvent; the problems involved are summarised by Bates. ${ }^{3}$ The use of this half-reaction for defining potential scales in non-aqueous media relative to aqueous media is complicated by the fact that the solvents used generally have Lewis-base characteristics appreciably different from those of water, which result in their forming with hydrogen ion more or less stable adducts, $(H \cdot \text { - solvent })^{+}$, as well as in a varying degree of solvation of hydrogen ion and/or its adduct. The resulting levelling effect in the case of Brønsted acids in aqueous media through the formation of the hydronium ion, $\mathrm{H}_{3} \mathrm{O}^{+}$, is wellknown; analogous effects are seen in other solvents.

Calculation of the solvation energy for the hydrogen ion in various solvents in connection with the reaction of equation (1) would facilitate potential scale comparison; however, the problem is still a formidable one. Izmailov ${ }^{26.27}$ has attempted to calculate the solution energy of hydrogen ion in a variety of solvents.

Hills ${ }^{23}$ has discussed the use of the hydrogen electrode as a potentiometric reference electrode in non-aqueous solutions.

\section{Hydrogen ion activity}

The difficulty of expressing hydrogen ion activity and concentration in aqueous solution in a usable, operational manner from electrometric $\mathrm{pH}$ measurement has been considered by Bates. ${ }^{3}$ The situation with respect to the interpretation of electrometrically measured $\mathrm{pH}$ numbers for non-aqueous media is far less well defined, ${ }^{4}$ although Bates and others are beginning to explicate $\mathrm{pH}$ scales for aqueous-organic and organic solvents.

In the present review, hydrogen ion concentrations will generally be given in terms of the analytical concentration of the hydrogen ion source added to the test system. Admittedly, such a purely operational approach constitutes a poor way of expressing hydrogen ion activity, but any other method would result in even more confusion with respect to interpretation.

\section{Classification of solvents}

Based on proton availability, solvents may be divided into three main groups, consisting of (1) protonic, (2) aprotic and (3) non-protonic compounds.

Protonic solvents, which contain more or less readily releasable protons and thus exhibit somewhat acidic properties in aqueous media, can themselves be subdivided into three sub-groups. The hydroxylic solvents, of which water is the most familiar member, include alcohols and glycols, which usually exhibit properties similar to those of water. The protogenic solvents are considerably stronger acids than water; the protophilic solvents are considerably stronger bases than water but may exhibit acidic properties, i.e., release protons, under some conditions.

Aprotic-frequently and incorrectly referred to as inert-solvents are those considered to have no acidic or basic properties. However, with the exception of pyridine and similar compounds which are actually aprotic, most other so-called inert solvents have very weak acidic or basic properties, e.g., dimethylsulphoxide is a much wcaker acid than water but is comparable in base strength.

Non-protonic solvents are totally devoid of hydrogen in their structure and consequently cannot act as acids in the Brønsted sense. They may, however, behave as Lewis acids or bases. Unfortunately, the scanty polarographic literature on 
non-protonic solvents, if fused salt media are excluded, has largely been devoted to liquid sulphur dioxide, in which the reduction of hydrogen ion has not been specifically investigated.

The autodissociation constants of some solvents are tabulated in Table I.

\begin{tabular}{|c|c|c|}
\hline Solvent & $\mathrm{pK}_{\mathbf{a u t o}}^{\prime}$ & $\mathrm{pK}_{\text {auto }}$ \\
\hline $\begin{array}{l}\text { Nitric acid } \\
\text { Sulphuric acid } \\
\text { Formic acid } \\
\text { Hydrofluoric acid } \\
\text { Acetamide } \\
\text { Ethylene glycol } \\
\text { Water } \\
\text { Acetic acid } \\
\text { Methanol } \\
\text { Formamide } \\
\text { Dimethylsulphoxide } \\
\text { Ethanol } \\
\text { 1-Propanol } \\
\text { Nitromethane } \\
\text { 2-Propanol } \\
\text { Ammonia (liquid) } \\
\text { Hydrogen sulphide } \\
\text { (first stage) }\end{array}$ & $\begin{array}{l}1 \cdot 2 \\
3 \cdot 1 \\
6 \cdot 2 \\
9 \cdot 7\left(0^{\circ}\right) \\
10 \cdot 5 \\
\text { ca. } 11 \\
14 \cdot 0 \\
14 \cdot 5 \\
16 \cdot 7 \\
16 \cdot 8 \\
\text { ca. } 17 \\
19 \cdot 1 \\
19 \cdot 4 \\
19 \cdot 5 \\
20 \cdot 8 \\
32 \cdot 5\left(-50^{\circ}\right) \\
32 \cdot 6\end{array}$ & $\begin{aligned} & 2 \cdot 58 \\
& 4 \cdot 37 \\
& 7 \cdot 7 \\
& 11 \cdot 4 \\
& 11 \cdot 9 \\
& \text { ca. } 12 \\
& 15 \cdot 7 \\
& 15 \cdot 9 \\
& 18 \cdot 3 \\
& 18 \cdot 3 \\
& \text { ca. } 18 \\
& 20 \cdot 6 \\
& 20 \cdot 8 \\
& 20 \cdot 9 \\
& 22 \cdot 3 \\
& 34 \cdot 2\end{aligned}$ \\
\hline
\end{tabular}

* For solvent, $\mathrm{HA} \rightleftarrows \mathrm{H}^{+}+\mathrm{A}^{-}, \mathrm{K}_{\mathrm{auto}}^{\prime}=\left[\mathrm{H}^{+}\right]\left[\mathrm{A}^{-}\right]=\mathrm{K}_{\mathrm{auto}}[\mathrm{HA}]$

$\dagger$ The values of $\mathbf{K}_{\mathrm{auto}}^{\prime}$ are mostly taken from reference 10 .

\section{EFFECT OF SOLVENT CHARACTERISTICS}

In addition to the effect of the chemical properties of the solvent, e.g., its acid-base strength, certain of its physical properties, especially its viscosity and dielectric constant, also influence the polarographic behaviour of organic and inorganic species.

\section{Standard and half-wave potentials}

By its influence on the extent and energy of solvation of the ions involved and on the degree of ion association, the dielectric constant of the solvent plays a rather important role in determining the standard potential of an oxidation-reduction couple and, as a result, its polarographic half-wave potential, $E_{1 / 2}$. The change of potential with solvent is complex, because not only does $E_{1 / 2}$ of the species under study, e.g., hydrogen ion, vary with the dielectric constant of the solvent but the standard potential of the reference couple (and hence the potential of the reference electrode) may also vary. If a system is transferred from one solvent to another, the change in $E_{1 / 2}$ (corrected for liquid junction potential and referred to a common standard) may be expressed as

$$
\left(E_{1 / 2}\right)_{2}-\left(E_{1 / 2}\right)_{1}=\left(E_{1}^{\circ}\right)_{2}-\left(E_{i}^{\circ}\right)_{1}+\frac{R T}{n F} \ln \frac{\left(f_{i}\right)_{2}}{\left(f_{i}\right)_{1}}-\frac{R T}{2 n F} \ln \frac{\left(D_{1}\right)_{2}}{\left(D_{i}\right)_{1}}
$$

where $f_{i}$ is the activity coefficient of the ion concerned in the solvent indicated and $D_{1}$ is its diffusion coefficient, and the other terms have their customary significance. If the ratios of the activity coefficients (referred to a common standard) and of the diffusion 
coefficients are close to unity, the difference in $E_{1 / 2}$ will equal that of the standard potentials, which is related to the difference between the solvation energies in the two solvents

$$
\left(E_{1}^{\circ}\right)_{2}-\left(E_{1}^{\circ}\right)_{1}=\frac{\left(\Delta G_{1}\right)_{2}-\left(\Delta G_{1}\right)_{1}}{Z_{1} F}
$$

where $z_{1}$ is the charge on the ion and $\Delta G_{1}$ is its solvation energy. On estimating the solvation energy from the Born equation

$$
-\Delta \mathrm{G}_{1}=\mathrm{Nz}_{1}^{2} \mathrm{e}^{2}\left(1-\epsilon^{-1}\right) / 2 \mathrm{r}_{1}
$$

where $\mathbf{N}$ is Avogadro's number, $\mathrm{e}$ is unit charge on the electron, $\epsilon$ is the dielectric constant of the solvent and $r_{i}$ is the radius of the ion, and substituting into equation (2), one obtains

$$
\left(\mathrm{E}_{1 / 2}\right)_{2}-\left(\mathrm{E}_{1 / 2}\right)_{1} \approx\left(\mathrm{E}_{1}^{\circ}\right)_{2}-\left(\mathrm{E}_{1}\right)_{1} \approx \frac{\mathrm{z}_{1} \mathrm{e}}{2 \mathrm{r}_{1}}\left(\frac{1}{\epsilon_{2}}-\frac{1}{\epsilon_{1}}\right)
$$

Thus, a linear relationship is expected between $\mathrm{E}_{1 / 2}$ and the reciprocal of the dielectric constant of the solvent concerned. This relationship must, however, be used with caution, because variation of $r_{1}$ with the solvent, which probably occurs, will certainly lead to deviations from linearity.

The ideal behaviour expressed by equation (5) should be most closely approached by a large ion with a minimum charge, e.g., +1 . The behaviour of the larger alkali metal ions, e.g., potassium(I), rubidium(I) and caesium(I), as well as that of such species as ferrocene and cobalticene, has been presumed to approximate ideality.

The standard potentials of many metal-metal ion couples have been determined with respect to the hydrogen electrode in a number of solvents (Table II). On the basis of the standard potentials of various large ion couples, the standard potential of hydrogen, referred to the aqueous hydrogen electrode, has been calculated for several solvents (Table III). Values based on $\mathrm{E}_{\mathrm{Na}}{ }^{\circ}$ are obviously out of line in some solvents;

\begin{tabular}{|c|c|c|c|c|c|c|c|c|}
\hline \multirow{2}{*}{ Couple } & \multicolumn{8}{|c|}{ Solvent } \\
\hline & $\mathrm{H}_{2} \mathrm{O}$ & $\mathrm{HCOOH}$ & $\mathrm{NH}_{3}(1)$ & $\mathrm{N}_{2} \mathrm{H}_{2}$ & $\mathrm{MeOH}$ & $\mathrm{EtOH}$ & $\mathrm{HCONH}_{2}$ & $\mathrm{CH}_{3} \mathrm{CN}$ \\
\hline $\mathrm{Li}^{+} / \mathrm{Li}$ & -3.05 & $-3 \cdot 48$ & & $-2 \cdot 20$ & -3.09 & -3.04 & & $-3 \cdot 23$ \\
\hline $\mathbf{K}^{+} / \mathbf{K}$ & -2.93 & $-3 \cdot 36$ & & -2.02 & -2.92 & & $-2 \cdot 87$ & $-3 \cdot 16$ \\
\hline $\mathbf{R} \mathbf{b}^{+} / \mathbf{R} \mathbf{b}$ & -2.93 & $-3 \cdot 45$ & & -2.01 & -2.91 & & -2.85 & $-3 \cdot 17$ \\
\hline $\mathrm{Cs}^{+} / \mathrm{Cs}$ & -2.92 & $-3 \cdot 44$ & & & & & & $-3 \cdot 16$ \\
\hline $\mathrm{Na}^{+} / \mathrm{Na}$ & $-2 \cdot 71$ & -3.42 & & -1.83 & -2.73 & $-2 \cdot 66$ & & -2.87 \\
\hline $\mathrm{Zn}^{2+} / \mathrm{Zn}$ & -0.76 & -1.05 & & -0.41 & -0.74 & -0.64 & -0.76 & -0.74 \\
\hline $\mathrm{Cd}^{2}+/ \mathrm{Cd}$ & -0.46 & -0.75 & & -0.10 & -0.26 & -0.38 & -0.41 & -0.47 \\
\hline $\mathrm{Pb}^{\mathrm{a}+} / \mathrm{Pb}$ & -0.13 & -0.72 & & +0.35 & $-0 \cdot 20$ & -0.15 & -0.19 & -0.12 \\
\hline $\mathbf{H}^{+} / \mathbf{H}_{2}$ & 0.00 & 0.00 & & 0.00 & 0.00 & 0.00 & 0.00 & 0.00 \\
\hline $\mathrm{Cu}_{2}+/ \mathrm{Cu}$ & +0.34 & $-0 \cdot 14$ & & & +0.49 & +0.21 & +0.28 & +0.28 \\
\hline $\mathrm{I}_{2} / \mathbf{I}^{-}$ & +0.54 & -0.03 & $+1 \cdot 4$ & & +0.36 & +0.31 & & +0.07 \\
\hline $\begin{array}{l}\mathrm{Ag}^{+} / \mathrm{Ag} \\
\mathrm{Br} / \mathrm{Br}^{-}\end{array}$ & $\begin{array}{l}+0.80 \\
+1.07\end{array}$ & $\begin{array}{l}-0.17 \\
+0.52\end{array}$ & +1.8 & & $\begin{array}{l}+0.76 \\
+0.84\end{array}$ & $\begin{array}{l}+0.75 \\
+0.78\end{array}$ & & $\begin{array}{l}+0.23 \\
+0.47\end{array}$ \\
\hline $\mathrm{Cl}_{2} / \mathrm{Cl}^{-}$ & +1.36 & +0.77 & $\begin{array}{r}1.0 \\
+2.0\end{array}$ & & +1.12 & +1.05 & & +0.58 \\
\hline
\end{tabular}
these values are generally more positive than those based on the standard potentials of

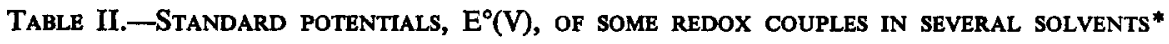

* Referred, as indicated, to the standard potential for hydrogen, $\mathrm{E}_{\mathbf{H}}^{\circ}$, in each solvent. 
the higher alkali metals. This positive difference in calculated $\mathrm{E}_{\mathbf{B}}{ }^{\circ}$, which amounts to $+0.2 \mathrm{~V}$ in formic acid and acetonitrile, and about $+0.3 \mathrm{~V}$ in methanol and hydrazine, indicates that the behaviour of $\mathrm{Na}(\mathrm{I})$ deviates from ideality as expressed above and that $\mathrm{E}_{\mathrm{Na}}{ }^{\circ}$ is actually more negative in these solvents than in water.

The standard potential of hydrogen in several nitriles and in acetone has been calculated by a spectrophotometric technique (Table IV).

TABLE III.-STANDARD POTENTIALS(V)* FOR HYDROgEN IN SEVERAL SOLVENTS

\begin{tabular}{|c|c|c|c|c|c|c|}
\hline \multirow{2}{*}{ Solvent } & \multicolumn{6}{|c|}{$E_{H}^{\circ}$ (in solvent) vs. N.H.E. (aq.) based $\dagger$ on } \\
\hline & $\mathrm{K}_{\mathrm{K}}^{\circ}$ & $\mathrm{E}_{\mathrm{K}}^{0}$ & $\overline{\mathbf{E}_{\mathrm{Rb}}^{\circ}}$ & $\mathbf{E}_{\mathbf{C} \mathbf{2}}^{\circ}$ & $\mathrm{E}_{\text {gerrocene }}^{0}$ & $\overline{E_{\text {cobelticene }}^{c}}$ \\
\hline $\begin{array}{l}\mathrm{HCOOH} \\
\mathrm{N}_{2} \mathrm{H}_{2} \\
\mathrm{MeOH} \\
\text { EtOH }\end{array}$ & $\begin{array}{l}+0.71 \\
-0.88 \\
+0.02 \\
-0.05\end{array}$ & $\begin{array}{l}+0.43 \\
-0.91 \\
-0.01\end{array}$ & $\begin{array}{l}+0.52 \\
-0.92 \\
-0.02\end{array}$ & +0.52 & -0.01 & -0.01 \\
\hline $\begin{array}{l}\mathrm{HCONH}_{2} \\
\mathrm{CH}_{3} \mathrm{CN}\end{array}$ & +0.45 & $\begin{array}{l}-0.06 \\
+0.23\end{array}$ & $\begin{array}{l}-0.08 \\
+0.24\end{array}$ & +0.24 & $\begin{array}{l}-0.15 \\
+0.15\end{array}$ & $\begin{array}{l}-0.15 \\
+0.15\end{array}$ \\
\hline
\end{tabular}

* Calculated from the data in Table II for the alkali metal couples and from the data of Strehlow et $a l,^{20}$ for the ferrocene and cobalticene couples.

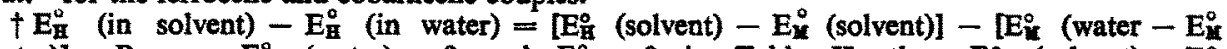
(water)]. Because $\mathrm{E}_{\mathrm{H}}^{\circ}$ (water) $\equiv 0$ and $\mathrm{E}_{\mathrm{H}}^{\circ}=0$ in Table II, then $\mathrm{E}_{\mathrm{H}}^{\circ}$ (solvent) $-\mathrm{E}_{\mathrm{H}}^{\circ}$ (water) $=\mathrm{E}_{\mathbf{M}}^{\circ}$ (water) $-\mathrm{E}_{\mathbf{H}}^{\circ}$ (solvent)

TABle IV.-STANDaRD POTENTIAL OF HYdRogen IN SOME NITRIIES AND ACETONE*

\begin{tabular}{lc}
\hline \multicolumn{1}{c}{ Solvent } & $\mathrm{E}_{\mathrm{B}}^{\circ}$ vs. N.H.E. (aq.) $\dagger, V$ \\
\hline Acetonitrile & +0.30 \\
Propionitrile & +0.26 \\
Isobutyronitrile & +0.25 \\
Benzonitrile & +0.29 \\
Phenylacetonitrile & +0.26 \\
Acetone & +0.24 \\
\hline
\end{tabular}

* Based on spectrophotometric titration of uncharged indicator bases, B, with perchloric acid. 1

$\dagger\left(E_{\mathrm{H}}^{\circ}\right)_{\text {org }}-\left(\mathrm{E}_{\mathrm{H}}^{\circ}\right)_{\text {mater }}=\left(\mathrm{E}^{\circ}\right)_{\text {org }}=0.059 \Delta \mathrm{pK}_{\mathrm{BH}^{+}}$, where $\Delta \mathrm{pK}_{\mathrm{BB}^{+}}=\left(\mathrm{pK}_{\mathrm{BH}^{+}}\right)_{\text {org }}-\left(\mathrm{pK}_{\mathrm{BB}}\right)_{\text {water }}$

\section{Acid dissociation constants}

The dielectric constant of the solvent also influences the apparent dissociation constants of acids. If an acid is dissolved in two solvents of equal acid-base strength but differing dielectric constant, the difference in apparent dissociation constant of the acid in the two solvents will depend on the charge types involved and on the difference in dielectric constant.

For an acid-base couple of the type $\mathrm{HB}^{+} / \mathrm{B}$, e.g., $\mathrm{NH}_{4}+/ \mathrm{NH}_{3}$, the electrostatic attraction between solvated $\mathrm{H}^{+}$and $\mathrm{B}$ (or $\mathrm{H}^{+}$and $\mathrm{HB}^{+}$) is negligible and so the dielectric constant change has no influence. In couples of the type HA/A-, e.g., HOAc/ $\mathrm{OAc}^{-}$, there is attraction between $\mathrm{H}^{+}$and $\mathrm{A}^{-}$, and the magnitude of $\mathrm{pK}_{\mathrm{a}}$ will change, i.e.,

$$
\Delta\left(\mathrm{pK}_{\mathrm{a}}\right)=\mathrm{k} \Delta(1 / \epsilon)
$$


where $\mathrm{k}$ is a constant which depends on the acid-base character of the solvents. For a couple of type $\mathrm{HA}^{-} / \mathrm{A}^{2-}$, e.g., $\mathrm{HCO}_{3}{ }^{-} / \mathrm{CO}_{3}{ }^{2-}$, where the acid is negatively charged, the influence of the dielectric constant change will be even greater, i.e.,

$$
\Delta\left(\mathrm{pK}_{\mathrm{a}}\right)=2 \mathrm{k} \Delta(1 / \epsilon)
$$

The acid dissociation constant data listed in Table $\mathrm{V}$ were collected from reference 10.

\section{Ion pair formation}

Ion pairing becomes appreciable in media of low dielectric constant. Appreciable association of the background electrolyte ions results in high solution resistance and in the consequent necessity for troublesome iR-drop corrections which, in some cases, may not completely compensate for the potential drop. ${ }^{51}$ In addition, association of the background electrolyte ions with the sample ions may lower the effective concentration of the latter and may complicate polarograms by the introduction of ion aggregates. involving background anions which may be reduced at different potentials. ${ }^{21}$ In media of very low dielectric constant, it may be difficult to find electrolytes with sufficient solubility and dissociation to serve as background electrolyte in maintaining low solution resistance.

\section{Current magnitude}

The viscosity, $\eta$, of the solvent influences the characteristics of the polarographic wave by altering the magnitude of the diffusion current through a change in diffusion coefficient. Because the diffusion current constant, $I$, is proportional to $D^{1 / 2}$, one obtains, on introducing the Stokes-Einstein equation into the Ilkovič equation,

$$
\left(\mathrm{I}_{\mathrm{i}}\right)_{2}\left(\mathrm{r}_{1}\right)_{2}^{1 / 2}(\eta)_{2}^{1 / 2}=\left(\mathrm{I}_{\mathrm{i}}\right)_{1}\left(\mathrm{r}_{1}\right)_{1}^{1 / 2}(\eta)_{1}^{1 / 2}=\mathrm{k}^{\prime}
$$

The latter equation predicts a linear relation between $I_{d}$ and $\eta^{-1 / 2}$ for different solvents.

\section{HYDROGEN ION REDUCTION IN AQUEOUS MEDIA}

The mechanism of electrochemical hydrogen ion reduction in aqueous solution is still a controversial subject. Reference has been made to Frumkin's review of the role of adsorption; the effect of other processes and factors has been discussed in depth, e.g., Kortüm and Bockris. ${ }^{37}$ There is still lack of general agreement as to the controlling steps even for the reduction of hydrogen ion on mercury, which has been so extensively investigated.

Many polarographic investigators tend to accept-at least implicitly-as the mechanism for hydrogen reduction on mercury the sequence of steps postulated by Heyrovský, ${ }^{22}$ which involves a reversible discharge of hydrogen ion to atomic hydrogen

$$
\mathrm{H}^{+}+\mathbf{e} \rightleftharpoons \mathbf{H}
$$

which then combines with a hydrogen ion

$$
\mathrm{H}+\mathrm{H}^{+} \rightarrow \mathrm{H}_{\mathbf{2}}^{+}
$$




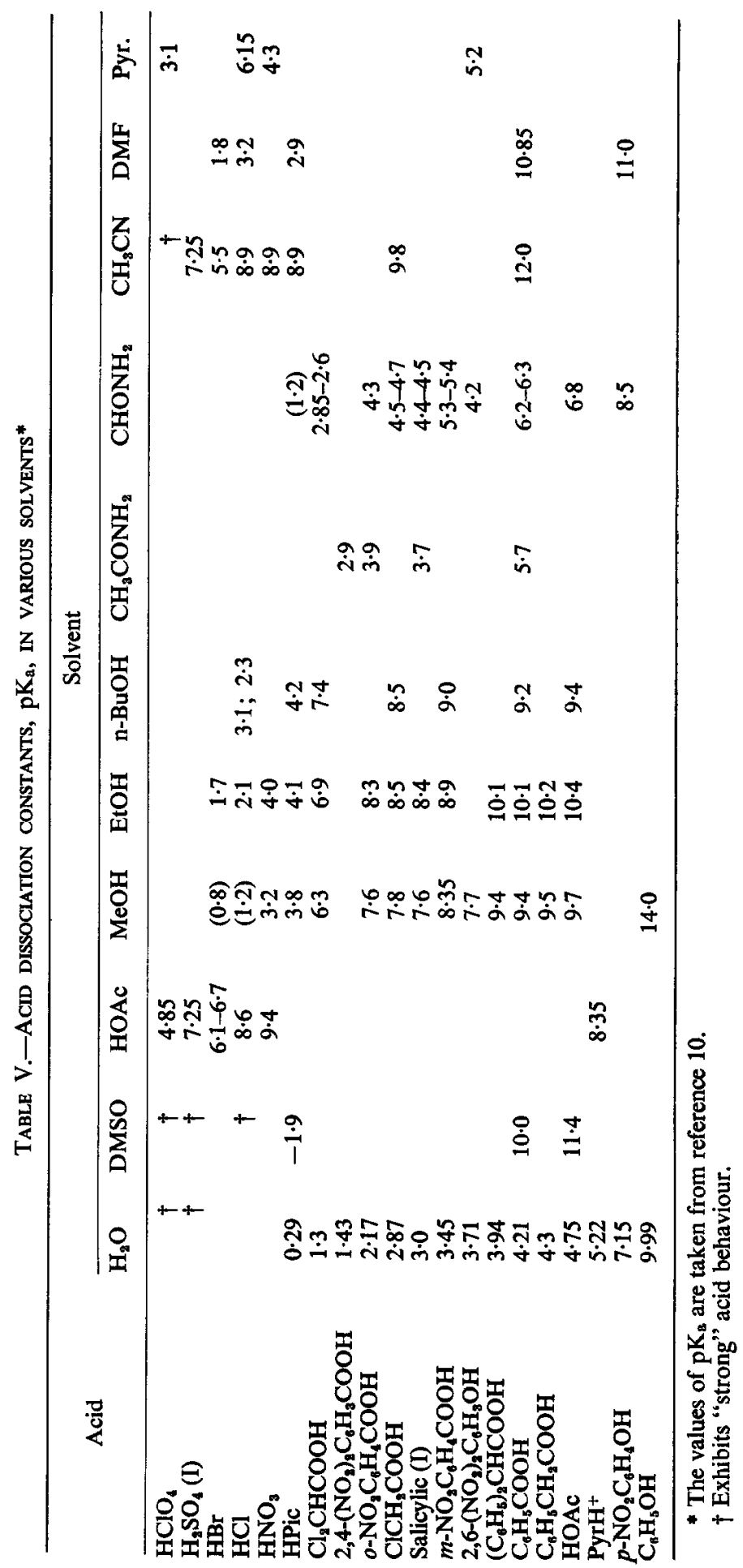


Reaction (10) is assumed to involve hydrogen atoms at the mercury surface and hydrogen ions in the solution with the $\mathrm{H}_{2}{ }^{+}$ions at the surface of the electrode being rapidly discharged or reduced to molecular hydrogen

$$
\mathrm{H}_{2}{ }^{+}+\mathbf{e} \rightarrow \mathrm{H}_{2}
$$

Although the current-potential equation derived on this basis fits the experimental facts, doubt has been raised concerning the correctness of the proposed mechanism. ${ }^{33}$

Frumkin has suggested a mechanism, in which the slow step is the reduction of hydrogen ion to adsorbed atomic hydrogen

$$
\mathrm{H}^{+}+\mathrm{e} \rightarrow \mathrm{H}_{\mathrm{ads}}
$$

This is followed by the rapid reaction

$$
\mathrm{H}_{\mathrm{ads}}+\mathrm{H}^{+}+\mathrm{e} \rightarrow \mathrm{H}_{2}(\mathrm{~g})
$$

The various mechanisms advanced for the hydrogen electrode reaction have been critically reviewed by Horiuti, ${ }^{24}$ who has also considered the relative roles of catalytic and electrochemical processes at the electrode. Breiter ${ }^{8}$ has discussed the kinetics of hydrogen evolution and dissolution at activated platinum metals.

\section{Kinetic waves}

The situation with respect to the kinetically-controlled currents observed in the reduction of weak acids, due to the dissociation equilibria of such acids and the generally considerably easier reduction of the undissociated acid, HA, than that of the corresponding anion, $\mathrm{A}^{-}$, is well known and has recently been ably reviewed by Brdička, Hanuš and Koutecký. ${ }^{\text {? }}$

\section{Catalytic hydrogen waves}

Catalytic hydrogen waves at the dropping mercury electrode have been discussed at length in the polarographic literature. In general, such waves have been assumed to be caused by the presence of an alternate path for the reduction of hydrogen ion, which has a lower activation energy than the normal process on mercury and therefore shows a lower hydrogen overpotential. The reaction path is usually assumed to be of the following type:

$$
\begin{gathered}
\mathrm{H}^{+}+\mathrm{Cat} \rightleftharpoons(\mathrm{H} \cdot \mathrm{Cat})^{+} \\
(\mathrm{H} \cdot \mathrm{Cat})^{+}+\mathrm{e} \rightarrow(\mathrm{H})+\mathrm{Cat}
\end{gathered}
$$

where the Cat species is constantly being regenerated and consequently may cause the reduction of hydrogen ion in amounts several times that of its own concentration. A typical "catalyst" of this type in aqueous solution would be pyridine with the intermediate species, which is reduced, being the pyridinium ion. .2.56 $^{2}$

The effect of metal ions and other organic species in producing such catalytic hydrogen waves is reviewed by Kolthoff and Lingane. ${ }^{33}$

It will be seen subsequently that in at least one organic solvent, pyridine, formation of a Lewis-type acid-base adduct between hydrogen ion and the solvent results in an overall reduction of the adduct rather than only of the hydrogen ion. 


\section{HYDROGEN ION REDUCTION IN PROTONIC SOLVENTS}

\section{Hydroxylic solvents}

Of the hydroxylic solvents, water is the only one in which the polarographic reduction of hydrogen ion has been extensively studied.

Dissociation constants of a number of acids in several alcoholic solvents are tabulated in Table V. Overall dissociation constants for perchloric, picric and benzoic acids, and 2,4-dinitrophenol have been reported in t-butyl alcohol. ${ }^{43}$

Migal and Grinberg ${ }^{45}$ determined the composition and stability of aquo complexes of hydrogen ion in an alcoholic medium by a polarographic method (presumably similar to the technique commonly used to determine the stability constants of complex species in aqueous media); the dissociation constants for the complex $\left[\mathrm{H}\left(\mathrm{H}_{2} \mathrm{O}\right)_{n}\right]^{+}$are reported to be $0.65,0.68,1.67$ and 10.51 for $\mathrm{n}=1,2,3$ and 4 , respectively, in ethanol, and $0.37,0.33$ and 3.41 for $\mathrm{n}=1,2$ and 3 , respectively, in methanol.

$E_{1 / 2}$ for solutions of "strong" acids (perchloric, hydrochloric) in ethanol-water solution containing tetramethylammonium chloride or lithium chloride background becomes more positive with increasing ethanol concentration; from the normal potential of the hydrogen electrode and the change in $E_{1 / 2}$, the overpotential for hydrogen ion reduction in ethanol (presumably at mercury) was estimated ${ }^{59}$ as $+0.1 \mathrm{~V}$.

In a study of the kinetics of hydrogen evolution on liquid and solid mercury in methanol solution, Bockris and coworkers ${ }^{6}$ found that the overpotential at a current density of $10^{-4} \mathrm{~A} . \mathrm{cm}^{-2}$ decreases by about $15 \mathrm{mV}$ at the freezing point of mercury. The heat of activation at the reversible potential was found to be about $1 \mathrm{~kg}$. cal. mole ${ }^{-1}$ lower on solid than on liquid mercury.

\section{Protogenic solvents}

Because protogenic solvents are generally much weaker bases than water, hydrogen ion would consequently be expected to be much more easily reduced in such solvents than in water. Indeed, the standard potential for hydrogen is about $0.5 \mathrm{~V}$ more positive in acetic acid than in water (Table III). The differentiation of acids, which exhibit "strong" behaviour in water, by acid solvents ( $c f$. Table V) has long been utilised in the titration of mixtures of such acids, e.g., the titration of perchloric, hydrochloric and sulphuric acid mixtures in glacial acetic acid.

Acetic acid (99.5\%) has been used as a solvent for the polarography of several cations; ${ }^{1}$ at potentials more negative than $-1.7 \mathrm{~V}$ vs. aqueous S.C.E., hydrogen is evolved from the solvent.

Dissociation constants of some acids in anhydrous formic acid have been calculated from potentiometric titration curves. Inorganic acids (presumably "strong" in water) remain strong in this solvent and are not differentiated as in acetic acid, while acetic, chloracetic, dichloracetic, salicylic and picric acids are so weak that they cannot be titrated. ${ }^{53}$ The quinhydrone electrode, which has been reported to be quite stable and reversible in anhydrous formic acid, has been used as a polarographic anode in this solvent. ${ }^{47}$ In general, the quinhydrone electrode functions as a hydrogen electrode in proton-active solvents, but not in solvents of low proton activity.

Kolthoff $^{31}$ has noted the general stabilisation of anions by hydrogen bonding, particularly in acid solvents,

$$
\mathbf{A}^{-}+\mathrm{HS} \rightleftharpoons(\mathrm{AHS})^{-}
$$


The stability of the resulting complex is greater than in water or hydroxylic solvents. The effect of such interaction on hydrogen reduction is apparent. Thus, $\mathrm{H}^{+}$or a Brønsted acid, HA, in an inert solvent may be stabilised by such conjugation, e.g., whereas hydrochloric acid is readily volatilised from acetonitrile solution by a purging gas stream, addition of an excess of tetra-alkylammonium halide to form a conjugate ion, $\mathrm{XHA}^{-}$, stabilises the solution.

In acid solvents, the reduction of hydrogen ion may proceed via protonated species produced on solute-solvent interaction, e.g.,

$$
\mathrm{HA}+\mathrm{HS} \rightleftharpoons \mathrm{H}_{2} \mathrm{~A}^{+}+\mathrm{S}^{-}
$$

where HA represents a weak acid added to the solvent HS. Basic solutes, e.g., amines, may also form protonated species, e.g.,

$$
\mathrm{B}+\mathrm{HS} \rightleftharpoons \mathrm{HB}^{+}+\mathrm{S}^{-}
$$

which may lead to hydrogen evolution.

\section{Protophilic solvents}

The solvation energy of hydrogen ion in strongly basic solvents is much greater than in water. In such solvents, hydrogen ion would be present in the form of the Lewis acid-base adduct, e.g., as $\mathrm{NH}_{4}{ }^{+}$in liquid ammonia. This would result in a more negative standard potential for hydrogen-and, correspondingly, more negative halfwave potential一in such solvents than in water. The standard potential in hydrazine is about $0.9 \mathrm{~V}$ more negative than in water and in formamide about $0.1 \mathrm{~V}$ more negative (Table III).

Liquid ammonia has been carefully investigated as a solvent for polarography and voltammetry by Laitinen and collaborators. ${ }^{38-41} \mathrm{E}_{1 / 2}$ for the reduction of ammonium ion at $-36^{\circ}$ is $-1.37 \mathrm{~V}$ vs. $\mathrm{Pb}-0.1 \mathrm{~N} \mathrm{~Pb}\left(\mathrm{NO}_{3}\right)_{2}$ reference electrode; ${ }^{41}$ the reduction product was thought to be free ammonium stabilised by amalgam formation.

Hammer and Lagowski ${ }^{21}$ reported a half-wave potential of $+1.0 \mathrm{~V} v s$. the "electron electrode" for the reduction of ammonium salts in liquid ammonia at a rotated platinum electrode at $-77^{\circ}$. Solutions of several ammonium salts gave different slopes for the $i_{\mathrm{d}} v s . \mathrm{C}$ plot in $0.1 \mathrm{M}$ solutions of the sodium salt of the corresponding anion, but the same slopes in $0 \cdot 1 M$ sodium perchlorate solution. This behaviour was ascribed to the formation of ion aggregates, e.g., ammonium perchlorate, which are reduced simultaneously with $\mathrm{NH}_{4}^{+}$. Re-use of the platinum electrodes without cleaning resulted in the appearance of a dark deposit on the electrode surface accompanied by a shift of $\mathrm{E}_{1 / 2}$ to more negative potential and a split in the wave; the deposit was ascribed to the formation of finely divided platinum.

Schaap and coworkers ${ }^{50}$ have thoroughly investigated anhydrous ethylenediamine as a solvent for electrochemical studies. Comparison of limiting conductances, $\Lambda_{0}$, in this solvent with those for the same salts in water reveals some significant differences. For several alkali metal salts, the ratio, $\left(\Lambda_{0}\right)_{\mathrm{en}} /\left(\Lambda_{0}\right)_{\mathrm{H}_{2} \mathrm{O}}$, has a mean value of 0.51 ; for silver (I) and thallium (I) salts, which solvate more strongly with the amine solvent, the mean ratio is 0.44 . The ratio for hydrochloric and nitric acids is about $0 \cdot 2$, which indicates that hydrogen ion is more strongly solvated in the amine solvent than in water. 
From the preliminary results of Schaap, ${ }^{50}$ the standard potential for hydrogen in ethylenediamine can be estimated to be $-0.5 \mathrm{~V}$ with respect to that in water.

Schöber and Gutmann ${ }^{52}$ reported an $\mathrm{E}_{1 / 2}$ of $-2.05 \mathrm{~V} v$ s. N.C.E. (aq.) for ammonium chloride in anhydrous ethylenediamine containing tetraethylammonium nitrate as background electrolyte.

Several amides have been used as polarographic solvents. Formamide and acetamide, because of their highly associated nature, are relatively poor hydrogen-bonding agents. ${ }^{61}$ If one or both of the amide hydrogens is replaced by an alkyl group, the resulting compounds should function much more readily as hydrogen-bonding agents; this view has lead to the investigation of $N$-methylacetamide and dimethylformamide (DMF) as solvents for polarography.

$\mathrm{E}_{1 / 2}$ for the reduction of strong acids in $N$-methylacetamide is $-1.53 \mathrm{~V} v$ s. S.C.E. (aq.); the depolarisation potentials of acetic acid and ammonium ion are reported to be -1.70 and $-1.85 \mathrm{~V}$, respectively. ${ }^{28}$

$\mathrm{E}_{1 / 2}$ for solutions of benzoic acid in DMF containing $0.2 \mathrm{M}$ tetrabutylammonium iodide is $-1.58 \mathrm{~V} v$ s. the mercury pool. ${ }^{60}$ Given and Peover ${ }^{19}$ report two waves for benzoic acid ( $c f$. Table VI) in DMF; the diffusion current constant for the first wave was about ten times that of the second wave, which was assumed to be from reduction of the undissociated acid. No wave was found for phenol.

\section{HYDROGEN ION REDUCTION IN APROTIC SOLVENTS}

The class of non-aqueous solvents most used for polarographic studies, especially for the reduction of hydrogen ion, has been that of the aprotic solvents. While many of these solvents can be considered to be "inert" for reactions involving many organic and inorganic species, there is probably no solvent which is truly inert towards hydrogen ion. The polarographic behaviour of a "strong" acid can furnish qualitative information regarding the basic properties of a solvent; thus, the levelling effect is more pronounced the more basic the solvent is compared to water, e.g., the situation in pyridine subsequently discussed.

Such a levelling effect is not observed in solvents which are much weaker bases than water, e.g., nitriles and ketones, with the result that the proton of a "strong" acid is much more readily reduced in such solvents than in water. In a very weakly basic solvent, the polarographic waves of "strong" acids, which overlap in water, are separated.

Acetonitrile, in which a large number of acids have been investigated, is a strongly differentiating solvent with respect to the strength of acids dissolved in it. Acids, which are "strong" and exhibit identical polarograms in water, e.g., perchloric, sulphuric, hydrochloric and nitric, give separate waves in acetonitrile (Table VI); the diffusion currents are proportional to the acid concentration. ${ }^{31} \mathrm{E}_{1 / 2}$ varies from $-0.70 \mathrm{~V} v \mathrm{~s}$. S.C.E. (aq.) for perchloric acid to $-2 \cdot 3 \mathrm{~V}$ for acetic acid. ${ }^{12,14,32}$ Some polyprotic acids behave as monobasic acids at the D.M.E. in exhibiting a single polarographic wave, e.g., in order of increasing (negative) $\mathrm{E}_{1 / 2}$ : sulphuric, oxalic and phosphoric acid; diffusion-current constants seem to decrease as $E_{1 / 2}$ becomes more negative. ${ }^{12}$ Controlled potential electrolysis of perchloric or acetic acid on the crest of the wave results in hydrogen evolution; perchlorates of aromatic amines give reduction waves with hydrogen evolution. ${ }^{12}$ Addition of an excess of free base apparently has no effect. $E_{1 / 2}$ for dichloranilinium ion is $0.06 \mathrm{~V}$ less negative than $E_{1 / 2}$ for hydrochloric acid and 


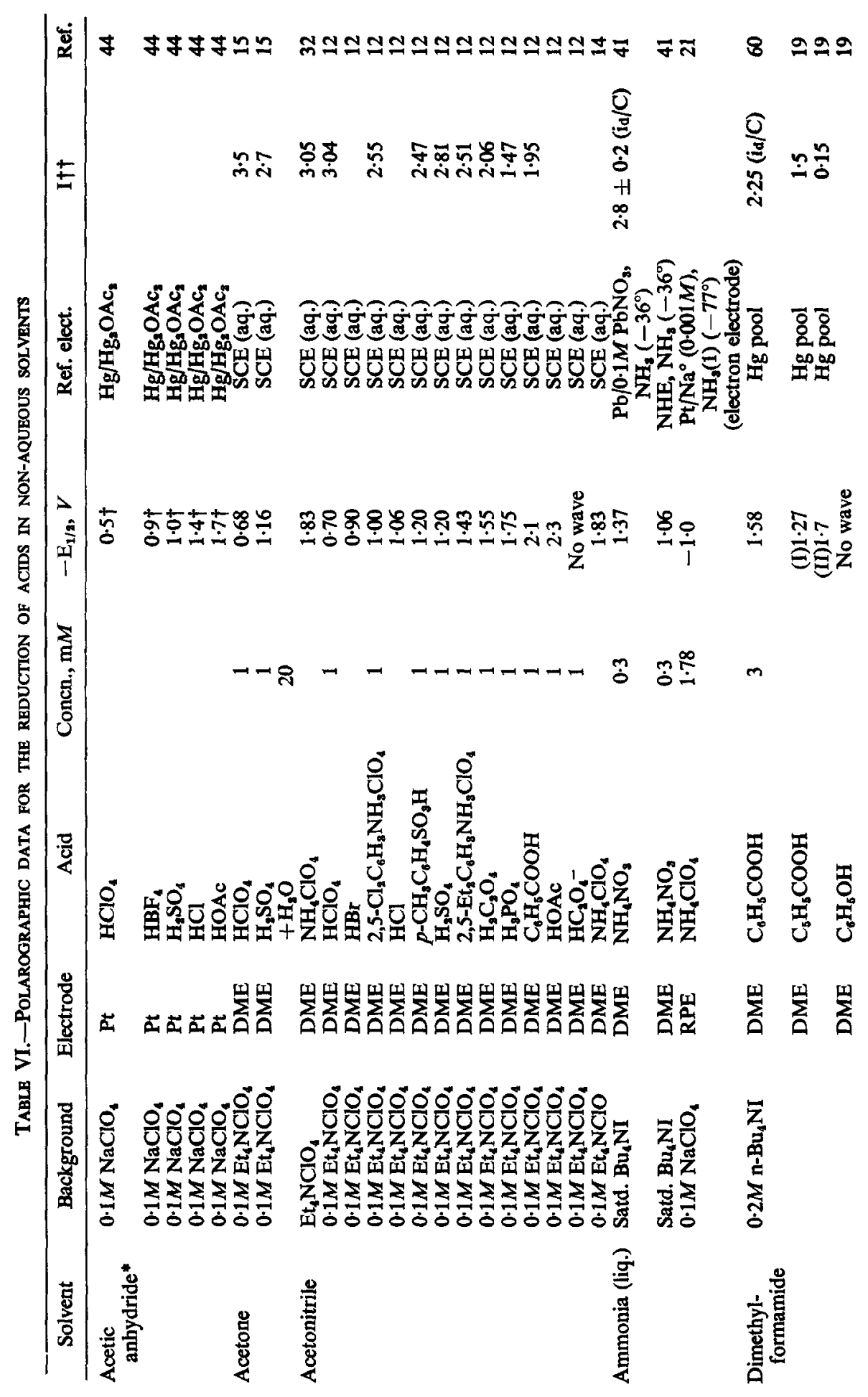




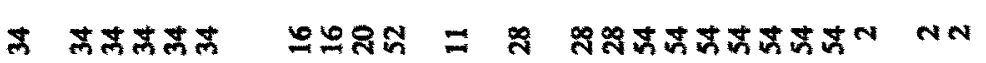

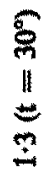

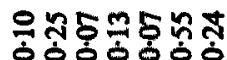

$H H+H H H H$

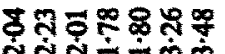

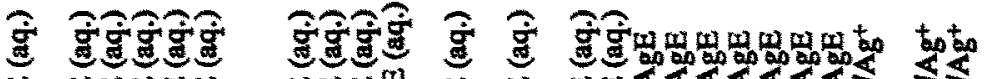

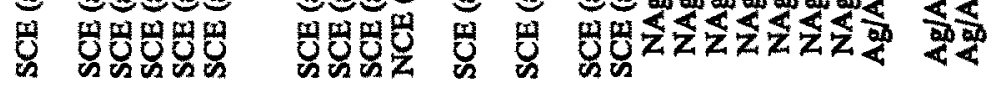

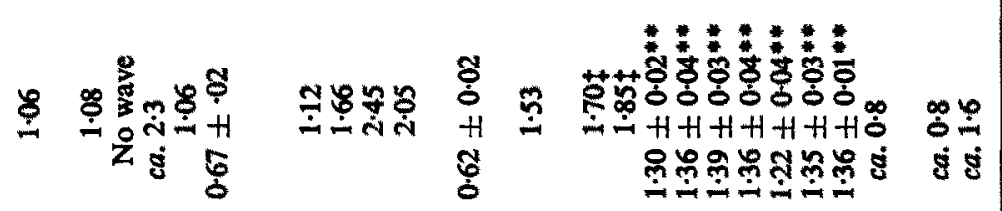

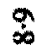

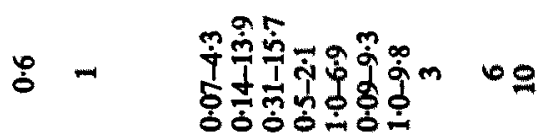

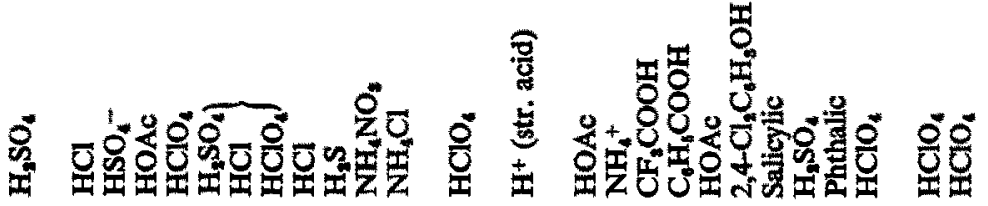

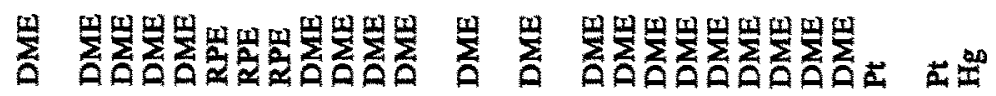

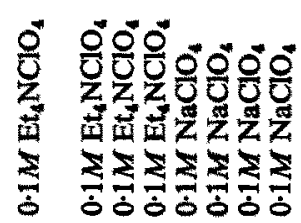

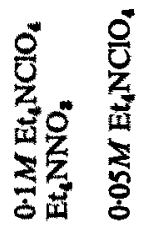

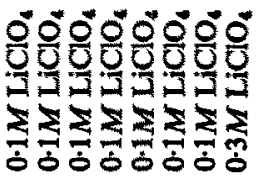
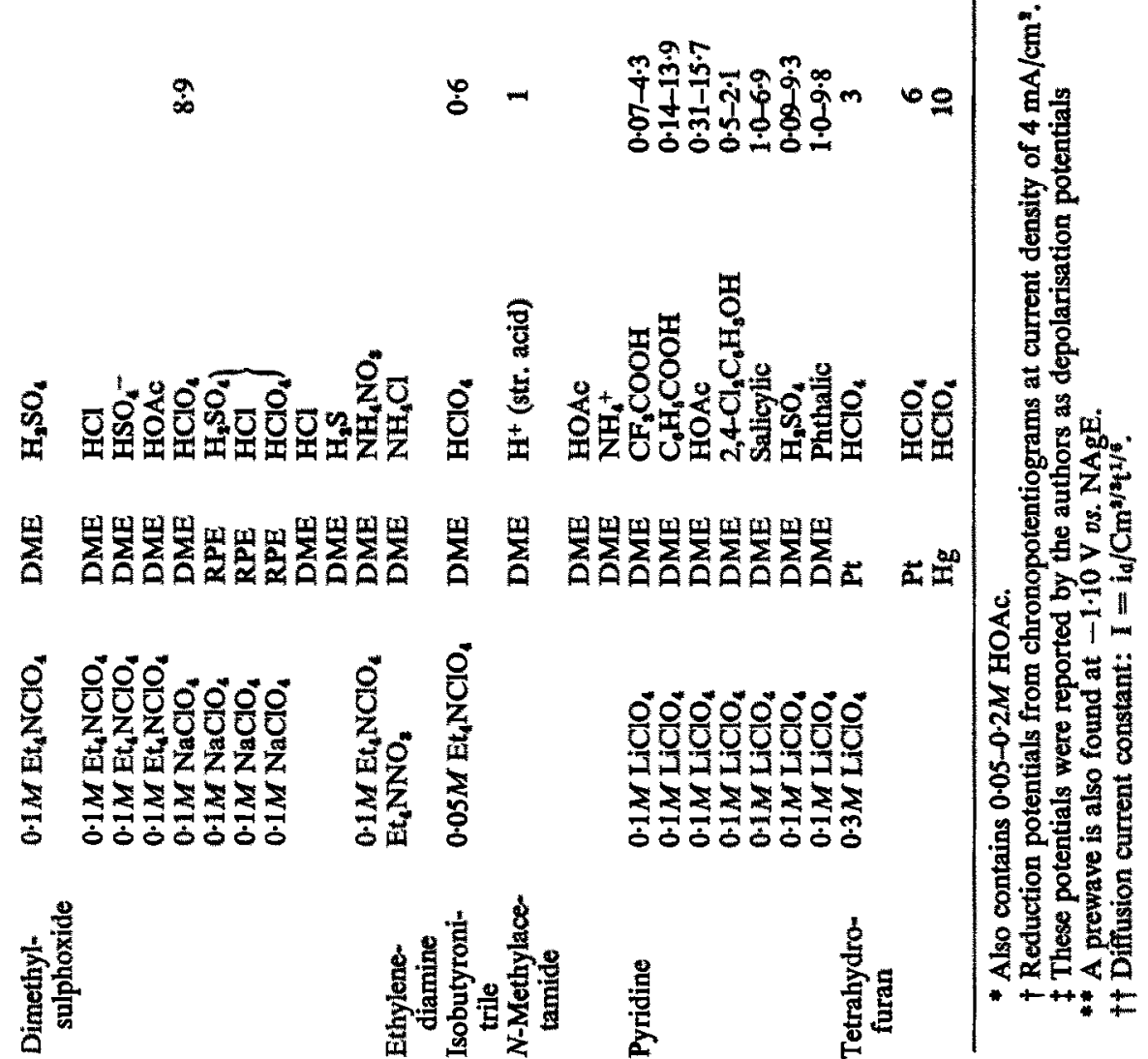
0.4 V less negative than $E_{1 / 2}$ for diethylanilinium ion, which is a much weaker acid.12 $E_{1 / 2}$ for ammonium ion is $0.8 \mathrm{~V}$ more negative than that for dichloranilinium ion. ${ }^{14.32}$ No waves are observed for bisulphate and bioxalate ions. ${ }^{12}$

The voltammetry of the hydrogen-perchloric acid system in acetonitrile has also been studied at platinised platinum electrodes. ${ }^{57}$

The reduction of perchloric acid in acetonitrile has been made the basis of an analytical method for the amperometric titration of bases, e.g., amines, dissolved in acetonitrile by means of a standard solution of perchloric acid in acetic acid. ${ }^{31}$

Addition of water, which is a much stronger base than acetonitrile, to acetonitrile solutions of a "strong" acid shifts the polarographic wave of the latter to a more negative potential. ${ }^{31.58}$ The effect is much larger than expected from the difference in base strength and is probably caused by the hydrogen overpotential on mercury increasing with water concentration. ${ }^{31}$

Kolthoff and Thomas ${ }^{36}$ report the hydrogen electrode to be suitable for the measurement of hydrogen ion activity in mixtures of sulphuric acid and tetraethylammonium bisulphate in acetonitrile.

In acetone containing $0 \cdot 1 M$ tetraethylammonium perchlorate, $\mathrm{E}_{1 / 2}$ is $0.48 \mathrm{~V}$ more positive for perchloric acid than for sulphuric acid and the diffusion current constant is about $30 \%$ greater for perchloric acid than for sulphuric acid (Table VI). ${ }^{15} E_{1 / 2}$ for perchloric acid shifts to a more negative potential on the addition of water.

Dimethylsulphoxide, as had been mentioned, is a much weaker acid than is water, but is comparable to water in base strength. ${ }^{35}$ Consequently, as might be expected, perchloric, sulphuric and hydrochloric acids are "strong" in dimethylsulphoxide and furnish identical polarograms at the D.M.E. as well as at the rotating platinum electrode (R.P.E.) (Table VI); $E_{1 / 2}$ for these acids is about $0.4 \mathrm{~V}$ more positive at platinum than at mercury. ${ }^{34} \mathrm{E}_{1 / 2}$ for hydrogen sulphide at the D.M.E. is about $0.6 \mathrm{~V}$ more negative than for the "strong" acids; ;6 acetic acid ${ }^{24}$ and ammonium ion ${ }^{20}$ behave as weak acids in this solvent (Table VI); no wave is observed for bisulphate ion. ${ }^{24}$

The chronopotentiometry of several acids was investigated in acetic anhydride solutions, which were $0 \cdot 1 M$ in sodium perchlorate and $0 \cdot 05-0 \cdot 2 M$ in acetic acid.44 Reduction (presumably chronopotentiometric quarter-wave) potentials at a platinum electrode increased, i.e., became more negative, in the following order: perchloric, tetrafluoboric, sulphuric, hydrochloric and acetic acids (Table VI). Chronopotentiometry of the solvent, which, as indicated, contained acetic acid, produced hydrogen gas and acetate ions at the cathode, and hydrogen gas and acetylium ions at the anode; the production of hydrogen gas at both electrodes was explained on the basis of proposed reaction intermediates.

In unbuffered $80 \%$ dioxan-water solution, $\mathrm{E}_{1 / 2}$ of mineral acids varies with the dissociation constant of the acid. ${ }^{46}$ For solutions more concentrated than $1.5 \mathrm{~m} M$ in weak acid (not specified), the polarogram exhibited three steps, which were attributed to successive reduction of the dioxan-oxonium ion, hydronium ion and the undissociated weak acid. ${ }^{46}$

$\mathrm{E}_{1 / 2}$ for a solution of perchloric acid in tetrahydrofuran containing $0.3 \mathrm{M}$ lithium perchlorate is reported to be $0.8 \mathrm{~V}$ more negative at a mercury electrode than at platinum (Table VI). ${ }^{2}$

Pyridine, because of its strong Lewis-base character, exhibits an apparently even more pronounced levelling effect than water. An essentially identical polarographic 
wave is obtained ${ }^{54}$ for pyridine solutions of acids, whose $\mathrm{pK}_{\mathrm{a}}$ values in aqueous solution vary from 7.9 to "very strong"; a small prewave is attributed to an impurity in the solvent, which reacts similarly to the solvent. Dibasic acids, such as sulphuric and phthalic, give a single wave, whose diffusion current constant is somewhat less than twice that found for all of the monobasic acids. Phenol (aqueous $\mathrm{pK}_{\mathrm{a}}=9.9$ ) does not give a wave; salicylic acid (aqueous $\mathrm{pK}_{\mathrm{a}}=3.0$ and 13.0) behaves like a monobasic acid. The polarographic wave was attributed to the reduction of pyridinium ion, formed in the reaction of acid with the solvent, by a one-electron attack on the pyridine ring, which results in the formation of a free radical, $\mathrm{pyrH}^{\circ}$, which dimerises to a tetrahydrobipyridyl.

The latter mechanism is apparently not affected by the addition of water, up to about $10 \%$ by volume; at water concentrations above $50 \%$, the reduction seems to proceed by the catalytic hydrogen evolution process observed in aqueous acid solutions containing traces of pyridine. ${ }^{17}$

Acknowledgement-The authors thank the U.S. Atomic Energy Commission and the Petroleum Research Fund of the American Chemical Society, which helped support their research on nonaqueous media.

Zusammenfassung-Die polarographische Reduktion von Wasserstoffionen, gebildet durch Dissoziation einer Brønstedsäure oder gegenwärtig in der nicht dissoziierten Brønstedsäure wird erörtert für Systeme, in welchen ein organisches Lösungsmittel anstelle von Wasser vorliegt.

Résumé-On passe en revue la réduction polarographique de l'ion hydrogène, fourni par la dissociation d'un acıde de Brønsted ou présent dans l'acide de Bronsted non dissocié, lorsqu'on met en jeu un solvant autre que l'eau.

\section{REFERENCES}

${ }^{1}$ G. B. Bachman and M. S. Astle, J. Amer. Chem. Soc., 1942, 64, 1303.

2 J. Badoz-Lambling and M. Sato, Acta Chim. Acad. Sci. Hung., 1962, 32, 191; Analyt. Abs., 1963, 10, 1320.

3 R. G. Bates, Determination of $p H$. John Wiley \& Sons, New York, 1964.

4 R. Bates in I. M. Kolthoff and P. J. Elving, Treatise on Analytical Chemistry, Part I, Vol. 1. Interscience Publishers, New York, 1959, pp. 361-404.

5 J. O’M. Bockris, J. Chim. phys., 1952, 49, C41; Chem. Abs., 1953, 47, $981 \mathrm{~g}$.

' J. O'M. Bockris, R. Parsons and H. Rosenberg, Trans. Faraday Soc., 1951, 47, 766.

7 R. Brdička, V. Hanus and J. Kautecký in P. Zuman and I. M. Kolthoff, Progress in Polarography, Vol. I. Interscience Publishers, New York, 1962, pp. 145-199.

${ }^{8} \mathrm{M}$. Breiter in E. Yeager, ed., Transactions of the Symposium on Electrode Processes. John Wiley \& Sons, New York, 1961, Chapter 17.

' G. Charlot, J. Badoz-Lambling and B. Trémillon, Electrochemical Reactions. Elsevier Publishing Co., Amsterdam, 1962.

${ }^{10} \mathrm{G}$. Charlot and B. Trémillon, Les reactions chimiques dans les solvants et les sels fondus. GauthierVillars, Paris, 1963.

11 J. F. Coetzee and J. L. Hedrick, J. Phys. Chem., 1963, 67, 221.

12 J. F. Coetzee and I. M. Kolthoff, J. Amer. Chem. Soc., 1957, 79, 6110.

${ }^{13}$ J. F. Coetzee and D. K. McGuire, J. Phys. Chem., 1963, 67, 1810.

${ }_{14}$ J. F. Coetzee, D. K. McGurre and J. L. Hedrick, ibid., 1963, 67, 1814.

15 J. F. Coetzee and W.-S. Siao, Inorg. Chem., 1963, 2, 14.

16 H. Dehn, V. Gutmann, H. Kurch and G. Schöber, Monatsh., 1962, 93, 1348.

${ }^{17}$ L. Floch, M. S. Spritzer and P. J. Elving, unpublished results.

${ }^{18}$ A. N. Frumkin in P. Delahay and C. W. Tobias, ed., Advances in Electrochemistry and Electrochemical Engineering. Interscience Publishers, Vol. 1, 1961; Vol. 3, 1963.

${ }^{19}$ P. V. Given and M. E. Peover, J. Chem. Soc., 1960, 385.

${ }^{20}$ V. Gutmann and G. Schöber, Z. analyt. Chem., 1957, 171, 339; Chem. Abs., 1960, 54, 7405e. 
${ }^{21}$ R. N. Hammer and J. J. Lagowski, Analyt. Chem., 1962, 34, 597.

${ }_{22}$ J. Heyrovsky, Coll. Czech. Chem. Comm., 1937, 9, 273.

${ }^{23}$ G. J. Hills in D. J. G. Ives and G. J. Janz, Reference Electrodes. Academic Press, New York, 1961, Chap. 10.

${ }^{24} \mathrm{~J}$. Horiut in E. Yeager, Transactions of the Symposium on Electrode Processes. John Wiley, New York, 1961, Chapter 2.

${ }^{25}$ W. Hubicki and M. Dabowska, Analyt. Chem., 1961, 33, 90.

${ }^{26}$ M. A. Izmailov, Doklady Akad. Nauk S.S.S.R., 1962, 149, 1103; Chem. Abs., 1963, 59, $4597 \mathrm{~b}$.

${ }^{27}$ Idem, ibid., 1963, 150, 120; Chem. Abs., 1963, 59, 7024e.

${ }^{28}$ L. A. Knecht and I. M. Kolthoff, Inorg. Chem., 1962, 1, 195.

${ }^{20}$ H. M. Koepp, H. Wendt and H. Strehlow, Z. Elektrochem., 1960, 64, 463.

so Idem. ibid., 1960, 64, 483.

s1 I. M. Kolthoff, J. Polarographic Soc., 1965, 10, 22.

${ }^{32}$ I. M. Kolthoff and J. F. Coetzee, J. Amer. Chem. Soc., 1957, 79, 870.

${ }^{33}$ I. M. Kolthoff and J. J. Lingane, Polarography. Interscience, New York, 1952.

${ }^{34}$ I. M. Kolthoff and T. B. Reddy, J. Electrochem. Soc., 1961, 108, 980.

${ }^{35}$ Idem, Inorg. Chem., 1962, 1, 189.

${ }^{36} \mathrm{I}$. M. Kolthoff and F. Thomas, in press; reported in reference 31.

${ }^{37}$ G. Kortüm and J. O'M. Bockris, Textbook of Electrochemistry. Elsevier, New York, 1951.

${ }^{38}$ H. A. Laitinen and C. J. Nyman, J. Amer. Chem. Soc., 1948, 70, 2241.

${ }^{39}$ H. A. Laitinen, ibid., 1948, 70, 3002.

${ }^{40}$ H. A. Laitinen and C. E. Shoemaker, ibid., 1950, 72, 663.

41 Idem, ibid., 1950, 72, 4975.

42 J. J. Lingane and O. L. Davis, J. Biol. Chem., 1941, 137, 567.

${ }^{43}$ L. Marple and J. S. Fritz, Analyt. Chem., 1963, 35, 1223.

44 W. B. Mather, Jr. and F. C. Anson, ibid., 1961, 33, 1634.

45 P. K. Migal and N. Kh. Grinberg, Uch. Zap., Kishinevsk. Gos. Univ., 1960, 56, 179; Chem. Abs., $1962,56,9709$ b.

46 Y. Okazaki, Bunseki Kagaku, 1962, 11, 991; Chem. Abs., 1962, 57, $14436 \mathrm{~b}$.

47 T. A. Pinfold and F. Sebba, J. Amer. Chem. Soc., 1956, 78, 2095.

${ }^{48}$ V. A. Pleskov, J. Phys. Chem. (U.S.S.R.), 1948, $22,351$.

49 Idem, Usp. Khim., 1947, 16, 254.

so W. B. Schaap, R. E. Bayer, J. R. Siefker, J. Y. Kim, P. W. Brewster and F. C. Schmidt, Record Chem. Progr., 1961, 22, 197.

51 W. B. Schaap and P. S. McKinney, Analyt. Chem., 1964, 36, 1251.

${ }^{52}$ G. Schöber and V. Gutmann, Monatsh., 1958, 89, 401.

${ }^{53}$ A. M. Shkodin, N. A. Izmailov and N. P. Dzyriba, Zhur. obshchei Khim., 1953, 23, 27.

${ }^{54}$ M. S. Spritzer, J. M. Costa and P. J. Elving, Analyt. Chem., 1965, 37, 211.

${ }^{55} \mathrm{H}$. Strehlow, Z. Elektrochem., 1952, 56, 827.

${ }_{56}$ P. C. Tompksin and C. L. A. Schmidt, J. Biol. Chem., 1942, 143, 643.

${ }^{67} \mathrm{~J}$. Vedel and B. Trémillon, J. Electroanalyt. Chem., 1960, 1, 241.

${ }^{58}$ A. A. Vlcek, Chem. Listy, 1954, 48, 1741; Chem. Abs., 1955, 49, 5158e.

so Idem, ibid., 1955, 49, 28; Coll. Czech. Chem. Comm., 1955, 20, 893; Chem. Abs., 1955, 49, 5158f.

${ }^{60}$ S. Wawzonek, E. W. Blaha, R. Berkey and M. E. Runner, J. Electrochem. Soc., 1955, 102, 235.

${ }^{61} \mathrm{~F}$. Willeboordse, Ph. D. Thesis, University of Amsterdam, 1959. 